$7^{\circ}$ Simposio Internacional de Investigación Multidisciplinaria / Ciencias de la Salud

7th Internationalm Symposium on Multidisciplinary Research / Health Sciences

\title{
CS-09 Caso probable de Zika. Reacción cruzada con infección previa por dengue
}

\author{
Probable Zika case. Cross-reaction with previous dengue infection \\ Fabio A. Recinos-López*, Sonia M. Pérez-Barrientos \\ Instituto Guatemalteco de Seguridad Social, Guatemala
}

*Autor al que se dirige la correspondencia: fabiorecinos@gmail.com

\section{Resumen}

$\mathrm{P}$ aciente femenina de 5 años de edad, de Santa Lucía Cotzumalguapa, Escuintla. Consulta por fiebre, malestar general, cefalalgia, exantema maculopapular eritematoso, vómitos y dolor abdominal en región epigástrica de 5 días de evolución. Datos positivos al examen físico: Temperatura axilar $38^{\circ} \mathrm{C}$, dolor abdominal difuso a la palpación profunda y dolor músculo esquelético en extremidades. Hematología: 9,290 leucocitos ( $45 \%$ de neutrófilos), hemoglobina $13.58 \mathrm{~g} / \mathrm{dL}$, plaquetas $26,400 / \mathrm{cc}$, velocidad de sedimentación $3 \mathrm{~mm} / \mathrm{h}$, proteína $\mathrm{C}$ reactiva $5 \mathrm{mg} / \mathrm{L}$, aspartato-aminotransferasa $148 \mathrm{U} / \mathrm{L}$, panel viral de hepatitis negativo, albumina sérica $2.7 \mathrm{~g} / \mathrm{dL}$. Radiografía de tórax: derrame pleural derecho. Por proceder de área endémica y llenar criterios de caso probable de dengue se hizo serología; dengue $\operatorname{IgM}(-), \operatorname{IgG}(+)$, chikungunya $\operatorname{IgM}(-), \operatorname{IgG}(-)$, zika $\operatorname{IgM}(+), \operatorname{IgG}(-)$. Se consideró como caso probable de zika y se solicitó pruebas confirmatorias. Antígeno para dengue (-), RT-PCR para chikungunya (-), RT-PCR para zika (-), con lo que se descartó la infección por zika. El tratamiento fue sintomático y la evolución fue satisfactoria, egresando al cuarto día. Al reevaluarla una semana después normalizó el valor de plaquetas y resolvió el derrame pleural. Es de recordar que los ensayos serológicos positivos son presuntivos, pudiendo existir reacción cruzada con infección previa por otros flavivirus (en este caso infección previa por dengue) y el diagnóstico deberá confirmarse o descartarse con pruebas de diagnóstico molecular.

Palabras claves: Flavivirus

\section{Abstract}

$\mathrm{F}$ emale patient, 5 years old, from Santa Lucía Cotzumalguapa, Escuintla. Consultation due to fever, malaise, headache, maculopapular erythematous rash, vomiting and abdominal pain in the epigastric region within 5 days of evolution. Positive data on physical examination: Axillary temperature $38^{\circ} \mathrm{C}$, diffuse abdominal pain on deep palpation and skeletal muscle pain in extremities. Hematology: 9,290/cc white blood cells ( $45.85 \%$ neutrophils), Hemoglobin: $13.58 \mathrm{~g} / \mathrm{dl}$, Platelets: 26,400 . Sedimentation rate: $3 \mathrm{~mm} / \mathrm{hr}$, C-reactive protein: $5 \mathrm{mg} / \mathrm{l}$, Aspartate aminotransferase: $148 \mathrm{U} / \mathrm{L}$, negative viral hepatitis panel, serum albumin: $2.7 \mathrm{~g} / \mathrm{dl}$. Chest $\mathrm{x}$-ray: right pleural effusion. For proceeding from endemic area and filling criteria of probable case of dengue serology samples were taken. Dengue: $\operatorname{IgM}(-), \operatorname{IgG}(+)$, Chikungunya: $\operatorname{IgM}(-), \operatorname{IgG}(-)$, Zika $\operatorname{IgM}(+), \operatorname{IgG}(-)$. It was considered a probable Zika case and confirmatory tests were requested. Dengue antigen (-), RT-PCR for Chikungunya (-), RT-PCR for Zika (-), which discarded Zika infection. The treatment was symptomatic and the evolution was satisfactory, leaving hospital at the fourth day. Upon reevaluation a week later, she normalized the platelet count and resolved the pleural effusion. It should be remembered that positive serological tests are presumptive, and there may be a cross-reaction with previous infection by other flaviviruses (in this case previous dengue infection) and the diagnosis should be confirmed or ruled out with molecular diagnostic tests.

Keywords: Flaviviruses 